Article

\title{
Bearing Capacity of Ring Foundations on Sand Overlying Clay
}

\author{
Chaowei Yang, Zhiren Zhu and Yao Xiao *(1) \\ Institute of Geotechnical Engineering, Hunan University, Changsha 410082, China; cwyang@hnu.edu.cn (C.Y.); \\ zhuzhiren@hnu.edu.cn (Z.Z.) \\ * Correspondence: yao_xiao@hnu.edu.cn
}

Received: 3 June 2020; Accepted: 3 July 2020; Published: 7 July 2020

\begin{abstract}
The vertical bearing capacity of rough ring foundations resting on a sand layer overlying clay soil is computed in this study by using finite element limit analysis (FELA). The sands and clays are assumed as elastoplastic models, obeying Mohr-Coulomb and Tresca failure criteria, respectively. Based on the FELA results, design charts are provided for evaluating the ultimate bearing capacity of ring foundations, which is related to the undrained shear strength of the clay, the thickness, the internal friction angle, the unit weight of the sand layer, and the ratio of the internal radius to the external radius of the footing. A certain thickness, beyond which the clay layer has a negligible effect on the bearing capacity, is determined. The collapse mechanisms are also examined and discussed.
\end{abstract}

Keywords: ring foundation; bearing capacity; sand overlying clay; finite element; limit analysis

\section{Introduction}

The bearing capacity of shallow foundations resting on homogeneous soil deposits has been investigated by Terzaghi [1], Meyerhof [2], Hansen [3], and Vesic [4]. In reality, however, naturally formed soil profiles beneath foundations are not homogeneous and are usually deposited in layers. The bearing capacity of footings placed on layered sand-clay media is an important consideration that arises frequently in foundation engineering [5]. Several studies have been conducted to investigate this problem. Terzaghi and Peck [6] proposed a load spread model in which the sand layer merely spreads the vertical load to the clayey stratum, and the bearing capacity of strip footing was determined. Meyerhof [7] and Hanna and Meyerhof [8] used the limit equilibrium approach to estimate the bearing capacity of footings on sand overlying clay. They assumed that a punching shear failure occurs in the sand layer. Okamura et al. [9] proposed a limit-equilibrium-based model for calculating the bearing capacity of a sand layer on clay. The sand layer is assumed to be in a state of passive failure, and the shear force acting on the sides of the sand block is taken into consideration. Lee et al. [10] developed a simplified conceptual model for predicting the bearing capacity of circular foundations placed on sand overlying clay soils. Expect for the theoretical solutions mentioned above, extensive studies have also been performed on the subject, by using upper bound limit analysis [11-13], finite element method [14-16], finite element limit analysis (FELA) [5,17], and model tests [18-20].

As summarized, previous studies have focused on the bearing capacity of strip footings, circular footings, and spudcan footings. More recently, studies have been conducted to investigate the bearing capacity of ring foundations, which are widely used to support offshore and onshore axisymmetrical structures (e.g., water towers, storage tanks, annular platforms, transmission towers, silos, and chimneys). Ohri et al. [21] performed model tests to investigate the behavior of ring footings in sand. Hataf and Razavi [22] presented results of laboratory tests for ring foundations on sand. Kumar and Ghosh [23] used the stress characteristics method to compute the bearing capacity factor $N_{\gamma}$ for ring foundations on sand. By using the same approach, Keshavarz and Kumar [24] 
determined the bearing capacity factors $N_{c}, N_{q}$, and $N_{\gamma}$ for both smooth and rough ring footings. On the basis of the numerical code FLAC, Zhao and Wang [25] calculated the bearing capacity factor $N_{\gamma}$ for ring foundations on cohesionless soil. Benmebarek et al. [26] also applied FLAC to estimate $N_{\gamma}$ for both smooth and rough ring footings, and the effect of the dilation angle was considered. Choobbasti et al. [27] evaluated the bearing capacity and settlement of ring footings by using the finite element code Plaxis. In addition, the bearing capacity of ring footings on reinforced sand has also been investigated experimentally and numerically [28,29]. Recently, Kumar and Chakraborty [30] obtained the bearing capacity factors for ring foundations by using FELA. Under undrained condition, the undrained bearing capacity factor $N_{c}$ for ring footings was calculated by using FLAC [31] and Plaxis packages [32-34]. By using the finite difference code FLAC3D, the influence of eccentric load on the bearing capacity of ring foundations was studied by Sargazi and Hosseininia [35].

A large number of studies, as reviewed above, have concentrated on the bearing capacity of ring foundations on many kinds of soil, yet particular attention has not been given to the complicated issue for sand overlying clay caused by interlayer condition. In this study, a series of numerical simulations using the FELA software OptumG2 [36] are applied to calculate upper and lower bounds on the bearing capacity for ring footings on sand overlying clay. These techniques, developed by Lyamin and Sloan [37,38] and Krabbenhoft et al. [39,40], utilize the conic optimization programming to compute the upper and lower bounds on the limit load. The methods do not require assuming a probable collapse mechanism, and more details about FELA can be found in Sloan [41]. A detailed parametric study is performed by varying the thickness and the friction angle of the sand layer, the undrained shear strength, and the ratio of the internal radius to the external radius of the footing. The results obtained from the present analysis are compared with literature studies. Based on the numerical computations, the results are presented in design charts, and the failure mechanisms are also discussed.

\section{Problem Definition}

The description of the bearing capacity problem is shown in Figure 1. A rigid ring foundation, with internal radius $\left(R_{i}\right)$ and external radius $\left(R_{0}\right)$, is placed on a sand layer that lies over a deep bed of clay. The sand layer, which has a thickness $(H)$, a unit weight $(\gamma)$, and an internal friction angle $(\varphi)$, is drained. The undrained shear strength of the clay is given by $c_{u}$. The ultimate bearing capacity of ring foundations on sand overlying clay can be described in the following dimensionless form:

$$
\frac{p_{u}}{\left(\gamma R_{0}\right)}=f\left(\frac{R_{i}}{R_{0}}, \frac{H}{R_{0}}, \frac{c_{u}}{\left(\gamma R_{0}\right)}, \varphi\right)
$$

where $p_{u}$ is the average limit pressure defined by the following:

$$
p_{u}=\frac{Q}{\pi\left(R_{0}^{2}-R_{i}^{2}\right)}
$$

where $Q$ is the ultimate vertical downward load.

In this paper, five different values of the ratio $R_{i} / R_{0}$, namely $0,0.25,0.33,0.5$, and 0.75 , are taken into consideration, covering most problems of practical interest [32-34]. The value of $H / R_{0}$ varies from 0.25 to 4 , corresponding to different values of $c_{u} / \gamma R_{0}$, namely $0.25,0.5,0.75,1,2,3,4$, and 5 . The internal friction angle $(\varphi)$ is set to $25^{\circ}, 30^{\circ}, 35^{\circ}, 40^{\circ}$, and $45^{\circ}$ [16]. 


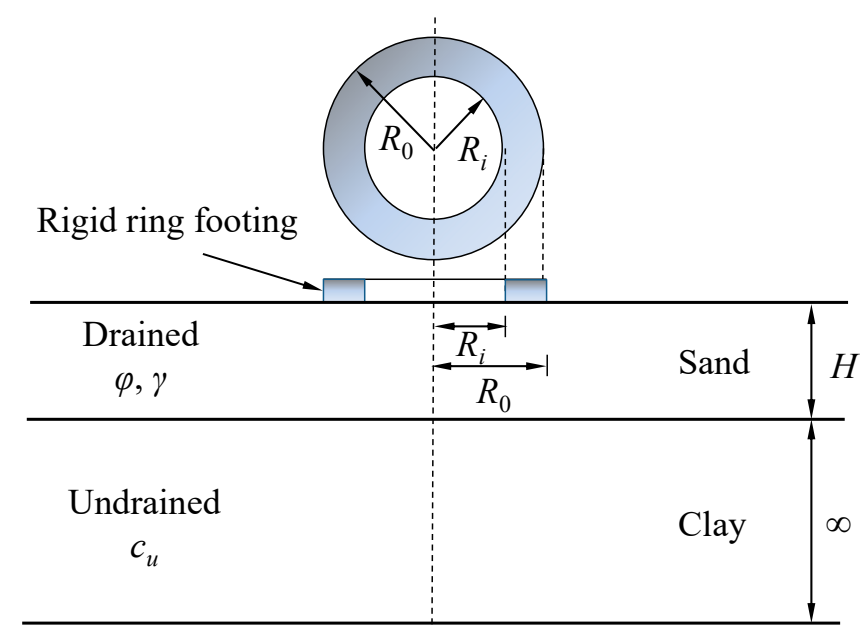

Figure 1. Problem definition of a rigid ring footing on sand overlying clay.

\section{Finite Element Limit Analysis}

The FELA method combines the upper and lower bound limit theorems of classical plasticity with the concept of finite elements, to deduce the failure load directly, which is developed by Lyamin and Sloan [37,38] and Krabbenhoft et al. [39,40]. The technique can model anisotropy, heterogeneity, complicated loading conditions, complex boundary shapes, and arbitrary geometries, as demonstrated by Sloan [41]. Compared to the conventional displacement FEA, the FELA method does not require performing a complete incremental analysis and the load-settlement curve to determine the limit load, showing high efficiency for the geotechnical stability problem analysis. In this study, the ultimate bearing capacity of ring footings on layered sand-clay media is computed by using the software OptumG2 [36], developed by the method of FELA. In the following section, the present numerical model of FELA in OptumG2 is summarized.

Figure 2 depicts a numerical model of the ring footing on sand overlying clay profile in OptumG2. Since the geometry of the problem is axis-symmetric, only half of the model domain is considered. In order to minimize boundary effects, the width and depth of the domain are set to $15 R_{0}$ and $10 R_{0}$, respectively. The external radius $\left(R_{0}\right)$ is kept at $3 \mathrm{~m}$, and five different values of the internal radius $R_{i}$, namely $0,0.75,1,1.5$, and $2.25 \mathrm{~m}$, are chosen. The bottom boundary of the problem is fixed, while the vertical boundaries of the model are only constrained in the horizontal direction.

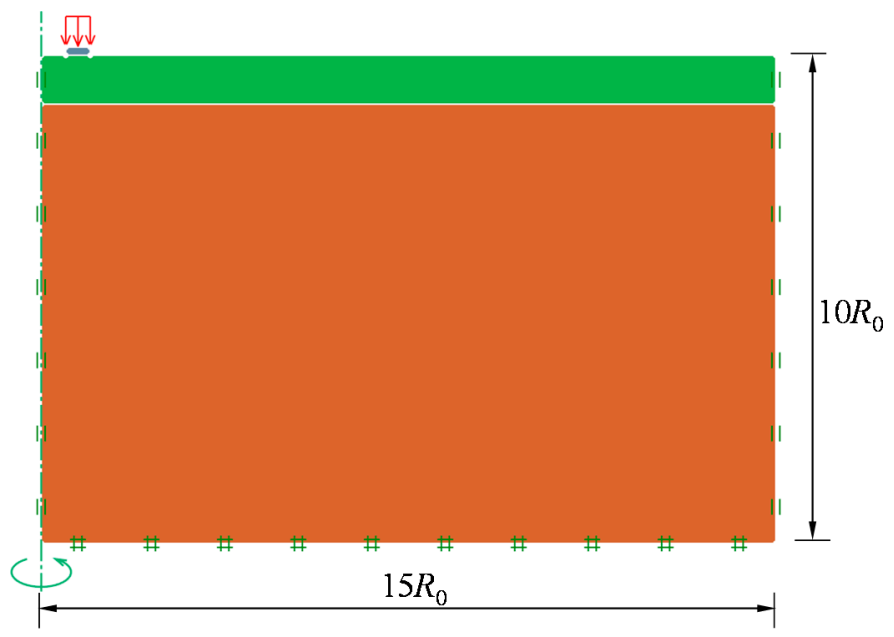

Figure 2. Numerical model of the problem in OptumG2.

The footing is considered to be a weightless rigid material, and the interface between the footing and the sand layer is assumed to be perfectly rough. The behavior of sands is modeled by using the 
linear elastic perfectly plastic Mohr-Coulomb material with an associated flow rule. The clay is treated as a linearly elastic-perfectly plastic material, obeying the Tresca criterion with an associated flow rule. Following the previous study by Park et al. [16], the Young's modulus $(E)$ of the sand layer and the clayey strata are set to 200 and $50 \mathrm{MPa}$, respectively. The Poisson's ratio $(v)$ used is 0.495 and 0.3 for clays and sands, respectively. The coefficient of lateral earth pressure $\left(K_{0}\right)$ of the clay is set to 1 , and $(1-\sin \varphi)$ for sands. It should be mentioned that the values of the elastic parameters and $K_{0}$ have a negligible effect on the ultimate bearing capacity of foundations [42,43]. The unit weight of the sand and the clay are both set to $\gamma=16 \mathrm{kN} / \mathrm{m}^{3}$, as mentioned by Kumar and Chakraborty [30].

In the numerical simulations, both upper and lower bound limit analyses are considered. In the UB limit analysis, the footing, the sand, and the clay are discretized into a six-noded triangular element, and discretized into a three-noded triangular element in the LB limit analysis. Automatic mesh adaptivity is used for all operations, and five adaptive steps are employed based on the software manual. A value of 1000 elements is selected in the first adaptivity iteration, and the elements increase to approximately 6000 in the final mesh. In order to improve the upper and lower bound solutions, the tool of mesh fan $5^{\circ}$ in the corner of ring footings is applied.

In the numerical simulations, both upper and lower bound limit analyses are considered. In the UB limit analysis, the footing, the sand, and the clay are discretized into a six-noded triangular element, and discretized into a three-noded triangular element in the LB limit analysis. Automatic mesh adaptivity is used for all operations, and five adaptive steps are employed based on the software manual. A value of 1000 elements is selected in the first adaptivity iteration, and the elements increase to approximately 6000 in the final mesh. In order to improve the upper and lower bound solutions, the tool of mesh fan $5^{\circ}$ in the corner of ring footings is applied.

\section{Comparisons of Previous Studies}

\subsection{For Circular Footings on Homogeneous Clay}

In Table 1 , the bearing capacity factor $\left(N_{c}\right)$ for a rough circular footing on homogeneous clay obtained from the present analysis is compared with existing solutions. Regarding the results of the theoretical exact solution reported by Meyehof [44], and the method of characteristics performed by Tani and Craig [45], Houlsby and Martin [46], and Martin [47], it can be seen that the values for $N_{c}$ lie between lower and upper bounds predicted by the present analysis, except for the values obtained by Tani and Craig [45]. The present values for $N_{c}$ correspond very closely to the semi-empirical solutions reported by Skempton [48], Hansen [3], and Vensic [4] and to the finite element methods conducted by Edwards et al. [49], Gourvenec et al. [50], Taiebat and Carter [51], and Lee et al. [33]. The upper bound solutions of Kusakabe et al. [52] and Salgado et al. [43] provide slightly greater values of $N_{c}$, compared to the upper bound of the present analysis. The lower bound values for $N_{c}$, obtained by Salgado et al. [43], Khatri and Kumar [53], and Kumar and Chakraborty [30] were found to be marginally smaller than the lower bound of the present study.

Table 1. Comparison of bearing capacity factor $\left(N_{c}\right)$ for a rough circular foundation on homogeneous clay.

\begin{tabular}{|c|c|c|c|}
\hline Meyerhof (1951) ${ }^{a}$ & 6.05 & Salgado et al. (2004) ${ }^{\mathrm{C}}$ & 6.227 \\
\hline Skempton (1951) b & 6.00 & Edwards et al. (2005) ${ }^{\mathrm{f}}$ & 6.09 \\
\hline Hansen $(1970)^{b}$ & 6.17 & Gourvenec et al. $(2006)^{f}$ & 5.96 \\
\hline Vesic (1973) ${ }^{b}$ & 6.17 & Khatri and Kumar (2009) e & 6.00 \\
\hline Kusakabe et al. (1986) ${ }^{\mathrm{C}}$ & 6.31 & Taiebat and Carter (2010) ${ }^{\mathrm{f}}$ & 6.166 \\
\hline Tani and Craig (1995) ${ }^{\mathrm{d}}$ & 6.34 & Kumar and Chakraborty (2015) $\mathrm{e}$ & 6.00 \\
\hline Houlsby and Martin (2003) d & 6.05 & Lee et al. $(2016)^{f}$ & 6.08 \\
\hline Martin (2004) ${ }^{d}$ & 6.05 & Present study e & 6.025 \\
\hline Salgado et al. (2004) $\mathrm{e}^{\mathrm{e}}$ & 5.856 & Present study ${ }^{c}$ & 6.058 \\
\hline
\end{tabular}

Note: ${ }^{\mathrm{a}}$ exact solution; ${ }^{\mathrm{b}}$ semi-empirical solution; ${ }^{\mathrm{c}}$ upper bound solution; ${ }^{\mathrm{d}}$ method of characteristics; ${ }^{\mathrm{e}}$ lower bound solution; ${ }^{\mathrm{f}}$ finite element method. 


\subsection{For Circular Footings on Homogeneous Sand}

The values of $N_{\gamma}$ for a rough footing on homogeneous sand are compared with the method of characteristics of Simone [54] and Martin [47]; the finite difference method of Erickson and Drescher [55]; the lower bound limit analysis of Lyamin et al. [56], Kumar and Khatri [57], and Kumar and Chakraborty [30]; the upper bound limit analysis of Lyamin et al. [56]; and the finite element method of Loukidis and Salgado [58]. These comparisons are listed in Table 2. It can be observed that the present values for $N_{\gamma}$ correspond very closely to the results of De Simone (1985), Martin (2004), Erickson and Drescher [55], Kumar and Khatri [57], Kumar and Chakraborty [30], and Loukidis and Salgado [58]. The lower bound values for $N_{\gamma}$, obtained by Lyamin et al. [56], are up to $9 \%$ under the presented lower bounds, while the upper bound values obtained by Lyamin et al. [56] are up to $28 \%$ above the presented upper bounds. The reason may be that Lyamin et al. [56] used the three-dimensional elements.

Table 2. Comparison of bearing capacity factor $\left(N_{\gamma}\right)$ for a rough circular foundation on homogeneous sand.

\begin{tabular}{|c|c|c|c|c|}
\hline & $\varphi=30^{\circ}$ & $\varphi=35^{\circ}$ & $\varphi=40^{\circ}$ & $\varphi=45^{\circ}$ \\
\hline De Simone (1985) ${ }^{a}$ & 15.73 & 42.38 & 124.46 & 418.93 \\
\hline Erickson and Drescher (2002) ${ }^{b}$ & - & 45.00 & 130.00 & 456.00 \\
\hline Martin (2004) ${ }^{a}$ & 15.54 & 41.97 & 124.10 & 419.44 \\
\hline Lyamin et al. (2007) ${ }^{c}$ & 14.10 & 37.18 & 106.60 & 338.00 \\
\hline Lyamin et al. (2007) d & 19.84 & 52.51 & 157.20 & 539.20 \\
\hline Loukidis and Salgado (2009) ${ }^{\mathrm{e}}$ & 15.80 & 42.00 & 122.20 & 405.50 \\
\hline Kumar and Khatri (2011) ${ }^{c}$ & 14.65 & 39.97 & 116.20 & 379.79 \\
\hline Kumar and Chakraborty $(2015)^{\mathrm{C}}$ & 14.80 & 40.10 & 116.57 & 380.08 \\
\hline Present study ${ }^{c}$ & 15.06 & 40.15 & 115.03 & 373.37 \\
\hline Present study $\mathrm{d}$ & 15.62 & 42.21 & 124.97 & 422.68 \\
\hline
\end{tabular}

Note: ${ }^{a}$ method of characteristics; ${ }^{b}$ finite difference method; ${ }^{c}$ lower bound solution; ${ }^{\mathrm{d}}$ upper bound solution; ${ }^{\mathrm{e}}$ finite element method.

\subsection{For Strip and Circular Footings on Sand Overlying Clay}

In Table 3, the results of the normalized bearing capacity, $p_{u} /(\gamma B)$, for a strip foundation on sand overlying clay are compared with the solutions reported by (1) Hanna and Meyerhof [8] by using the semi-empirical solution, (2) Michalowski and Shi [12] by using the upper bound rigid-block method, and (3) Shiau et al. [3] by using finite-element upper- and lower-bound limit-analysis methods. The present result is particularly close to those of Shiau et al. [3]. Both solutions of Hanna and Meyerhof [8] and Michalowski and Shi [12] overestimate the bearing capacity $p_{u} /(\gamma B)$ by up to $16 \%$ and $22 \%$ compared to the presented upper bounds and lower bounds, respectively.

Table 3. Comparison of normalized bearing capacity, $p_{u} /(\gamma B)$, for a rough strip foundation on sand overlying clay $\left(H / B=2, \varphi=45^{\circ}\right)$.

\begin{tabular}{ccccccc}
\hline & \multicolumn{7}{c}{$\boldsymbol{c}_{\boldsymbol{u}} / \gamma \boldsymbol{B}$} \\
\cline { 2 - 7 } & $\mathbf{0 . 5}$ & $\mathbf{1 . 0}$ & $\mathbf{2 . 0}$ & $\mathbf{3 . 0}$ & $\mathbf{4 . 0}$ & $\mathbf{5 . 0}$ \\
\hline Hanna and Meyerhof (1980) $^{\mathrm{a}}$ & 18.28 & 27.00 & 41.55 & 51.23 & 59.62 & 67.69 \\
Michalowski and Shi (1995) $^{\mathrm{b}}$ & 20.06 & 26.36 & 41.06 & 52.21 & 61.24 & 68.82 \\
Shiau et al. (2003) $^{\mathrm{b}}$ & 20.71 & 27.81 & 38.80 & 48.97 & 57.84 & 66.39 \\
Shiau et al. (2003) $^{\mathrm{c}}$ & 16.17 & 23.44 & 34.59 & 43.95 & 52.34 & 59.43 \\
Present study b $^{\mathrm{c}}$ & 16.85 & 24.79 & 36.90 & 46.91 & 55.89 & 64.09 \\
Present study $^{\mathrm{c}}$ & 15.59 & 23.15 & 34.43 & 43.59 & 51.74 & 59.97 \\
\hline
\end{tabular}

\footnotetext{
Note: ${ }^{\mathrm{a}}$ limit equilibrium method; ${ }^{\mathrm{b}}$ upper bound solution; ${ }^{\mathrm{c}}$ lower bound solution.
} 
Table 4 provides the obtained values of $p_{u} /\left(\gamma R_{0}\right)$ for a circular foundation on layered sand-clay media and compares them with the analyses of Kumar and Chakraborty [30] using the lower bound solution and Okamura et al. [9] using the limit equilibrium method. The comparisons of the present results have been also provided with the centrifuge test results of Okamura et al. [19]. It can be observed that the present results compare reasonably well with the results of Okamura et al. $[9,19]$ and Kumar and Chakraborty [30].

Table 4. Comparison of $p_{u} /\left(\gamma R_{0}\right)$ for a rough circular foundation on sand overlying clay $\left(\varphi=40^{\circ}\right)$.

\begin{tabular}{|c|c|c|c|c|c|c|c|}
\hline$R_{0}(\mathrm{~m})$ & $H / R_{0}$ & $c_{u} / \gamma \boldsymbol{R}_{\mathbf{0}}$ & $\begin{array}{l}\text { Present } \\
\text { Study }^{\mathrm{a}}\end{array}$ & $\begin{array}{l}\text { Present } \\
\text { Study }\end{array}$ & $\begin{array}{l}\text { Kumar and Chakraborty } \\
\qquad(2015)^{b}\end{array}$ & $\begin{array}{l}\text { Okamura et al. } \\
(1997)^{c}\end{array}$ & $\begin{array}{l}\text { Okamura et al. } \\
\text { (1998) }^{d}\end{array}$ \\
\hline \multirow[t]{18}{*}{1.5} & 0 & 1.61 & 9.70 & 9.76 & 9.71 & 10.00 & 10.71 \\
\hline & & 3.01 & 18.14 & 18.24 & 18.09 & - & 19.27 \\
\hline & & 5.15 & 30.03 & 31.21 & 30.97 & - & 32.88 \\
\hline & & 6.26 & 37.71 & 37.94 & 37.59 & - & 39.12 \\
\hline & 1 & 0.75 & 11.82 & 12.04 & 14.07 & - & 10.69 \\
\hline & & 3.05 & 26.47 & 27.14 & 29.78 & 28.90 & 31.57 \\
\hline & & 5.19 & 36.60 & 37.66 & 44.17 & - & 52.45 \\
\hline & & 6.26 & 41.08 & 42.27 & 51.30 & - & 62.61 \\
\hline & 2 & 0.80 & 33.98 & 34.85 & 46.92 & 31.95 & 25.23 \\
\hline & & 1.20 & 40.42 & 41.51 & 55.79 & 37.01 & 31.98 \\
\hline & & 3.21 & 60.34 & 62.40 & 78.14 & 58.30 & 58.43 \\
\hline & & 5.15 & 73.29 & 76.05 & 96.86 & 73.30 & 87.12 \\
\hline & 3 & 2.45 & 106.62 & 111.14 & 109.02 & - & 84.65 \\
\hline & & 3.54 & 111.53 & 125.53 & 118.52 & 103.00 & 103.75 \\
\hline & & 5.84 & 114.89 & 125.80 & 131.73 & 141.00 & 152.05 \\
\hline & 4 & 1.63 & 114.67 & 124.82 & 131.13 & 129.31 & 112.54 \\
\hline & & 1.85 & 115.01 & 125.19 & 134.62 & 133.80 & 117.04 \\
\hline & & 3.67 & 114.53 & 124.93 & 132.46 & 125.00 & - \\
\hline
\end{tabular}

Note: ${ }^{\mathrm{a}}$ upper bound solution; ${ }^{\mathrm{b}}$ lower bound solution; ${ }^{\mathrm{c}}$ using centrifuge test; ${ }^{\mathrm{d}}$ limit equilibrium method.

\section{Results and Discussion}

The values of $p_{u} /\left(\gamma R_{0}\right)$ for ring footings on sand overlying clay from FELA are depicted graphically in Figures 3-6. The maximum error of the upper and lower bound analyses is restricted within $9.6 \%$, and the smaller values are obtained at small $H / R_{0}$ ratios. Hence, average values of the upper and lower bound bearing capacity $p_{u} /\left(\gamma R_{0}\right)$ were determined and are employed in the following discussions. In addition, Equation (3) can be used to compute the error between UB and LB solutions.

$$
\text { Error }=\frac{2(U B-L B)}{(U B+L B)} \times 100 \%
$$
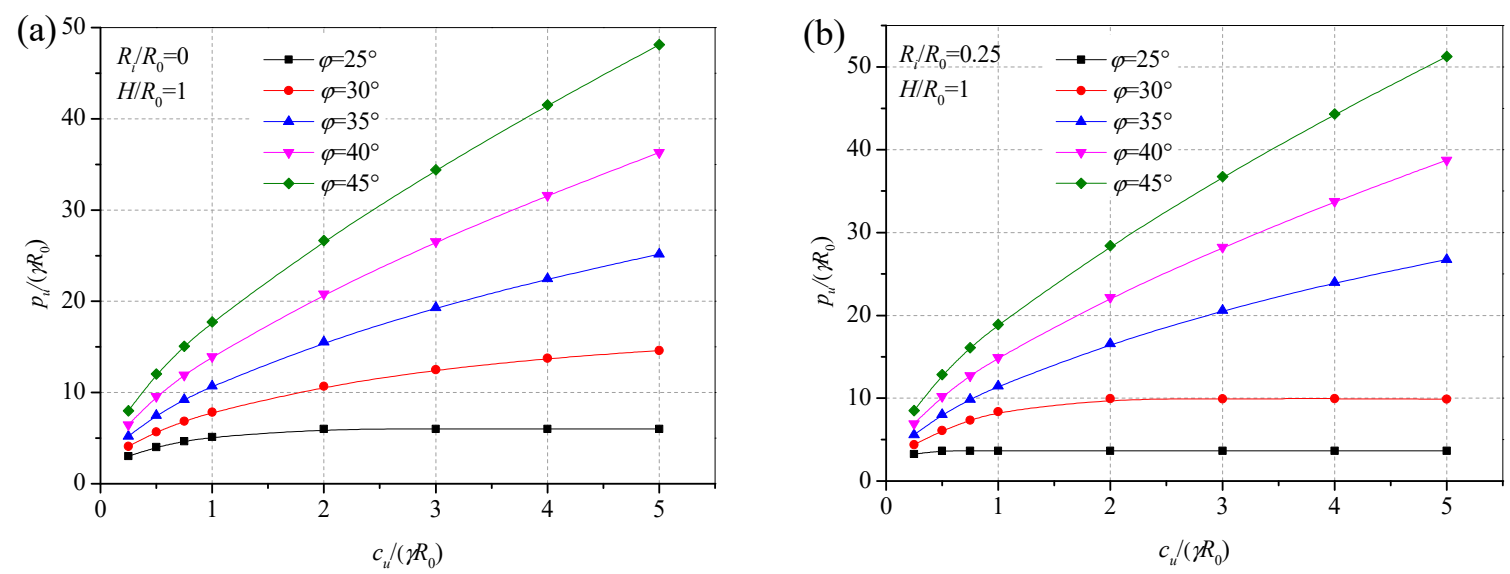

Figure 3. Cont. 

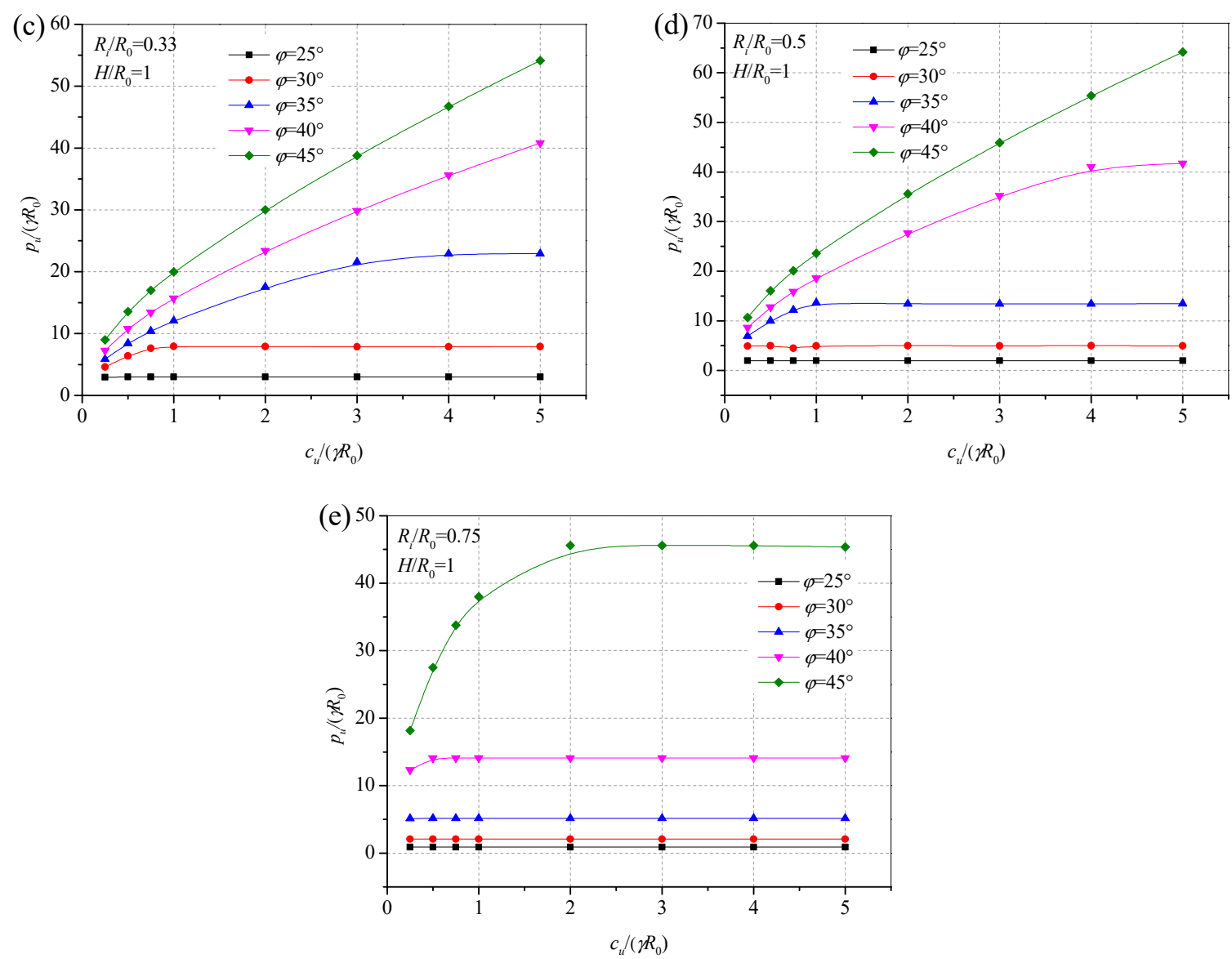

Figure 3. Variation in the normalized bearing capacity, $p /\left(\gamma R_{0}\right)$, with $c_{u} /\left(\gamma R_{0}\right)$ and $\varphi$ for $H / R_{0}=1$ with (a) $R_{i} / R_{0}=0$, (b) $R_{i} / R_{0}=0.25$, (c) $R_{i} / R_{0}=0.33$, (d) $R_{i} / R_{0}=0.5$, and (e) $R_{i} / R_{0}=0.75$.
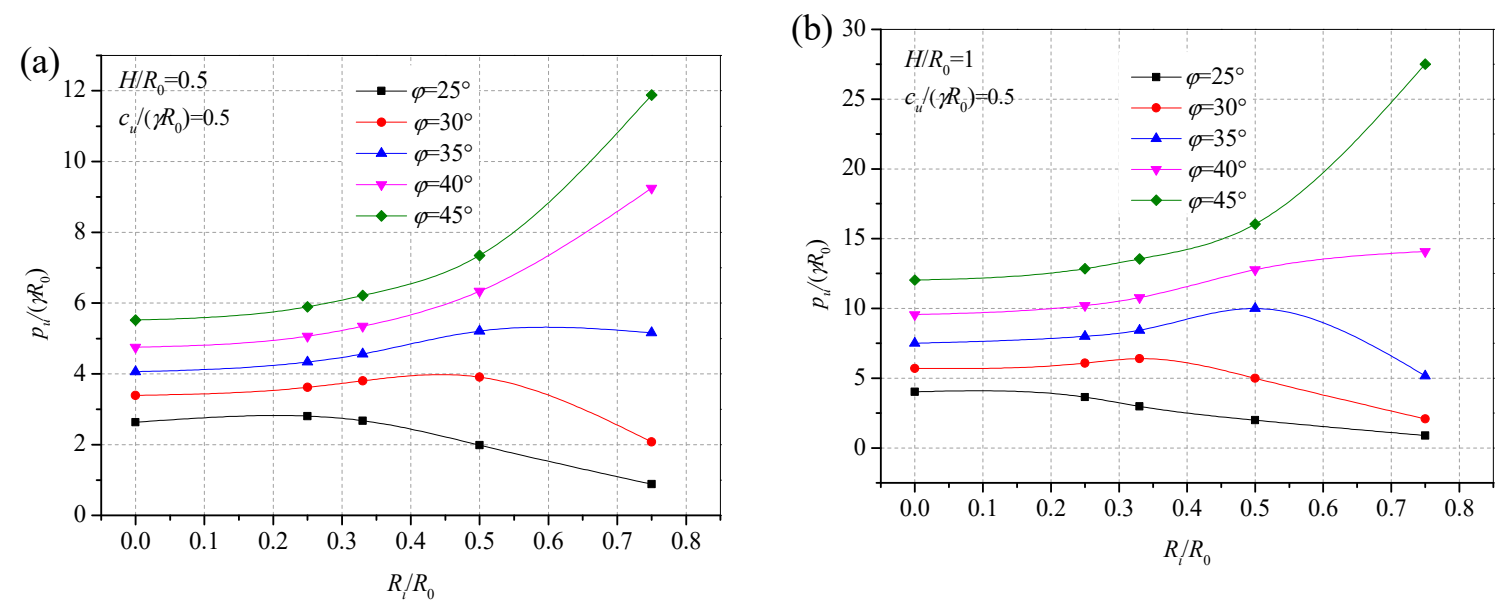

Figure 4. Cont. 

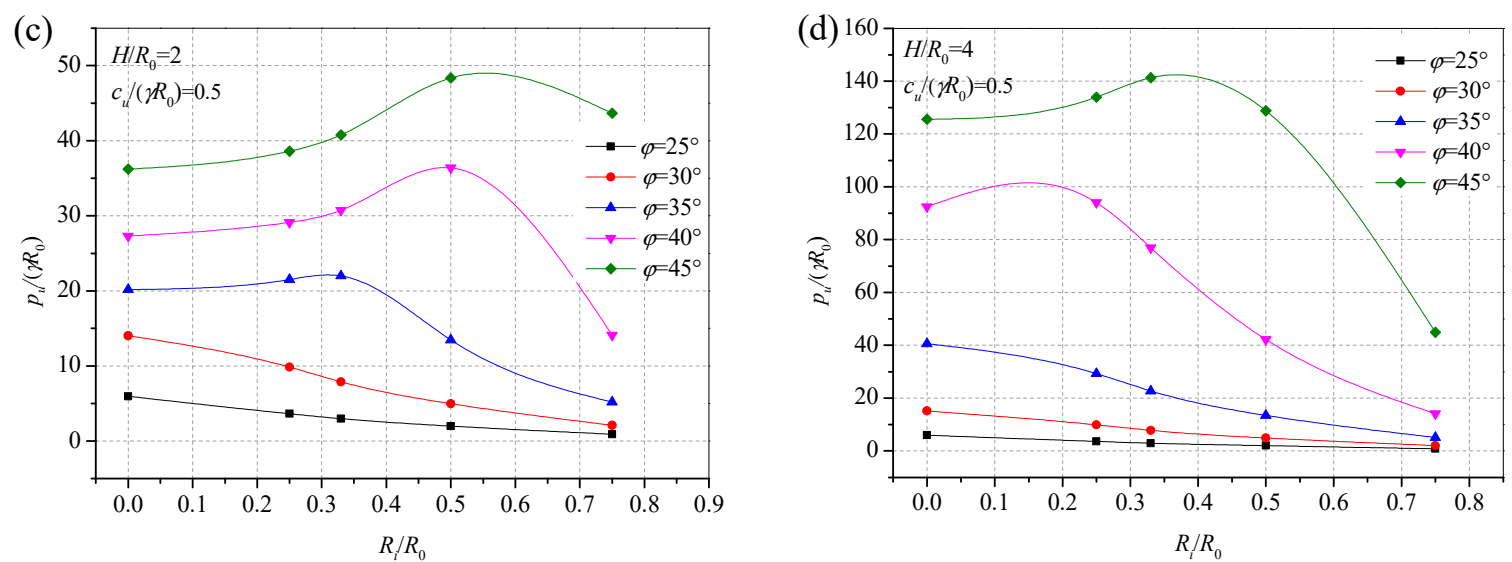

Figure 4. Variation in the normalized bearing capacity, $p /\left(\gamma R_{0}\right)$, with $R_{i} / R_{0}$ and $\varphi$ for $c_{u} /\left(\gamma R_{0}\right)=0.5$ with (a) $H / R_{0}=0.5$, (b) $H / R_{0}=1$, (c) $H / R_{0}=2$, and (d) $H / R_{0}=4$.
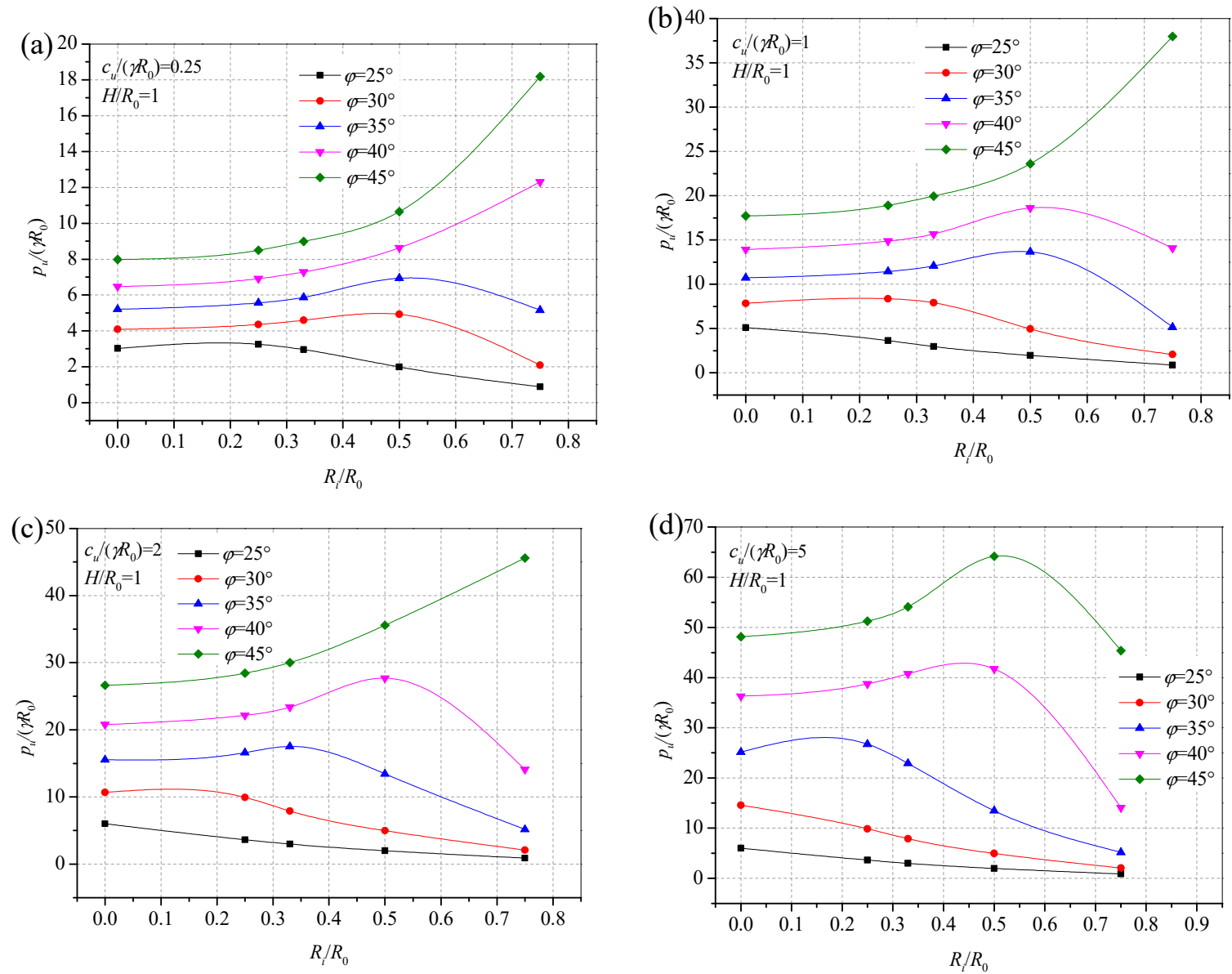

Figure 5. Variation in the normalized bearing capacity, $p /\left(\gamma R_{0}\right)$, with $R_{i} / R_{0}$ and $\varphi$ for $H / R_{0}=1$ with (a) $c_{u} /\left(\gamma R_{0}\right)=0.25$, (b) $c_{u} /\left(\gamma R_{0}\right)=1,(\mathbf{c}) c_{u} /\left(\gamma R_{0}\right)=2$, and (d) $c_{u} /\left(\gamma R_{0}\right)=5$. 

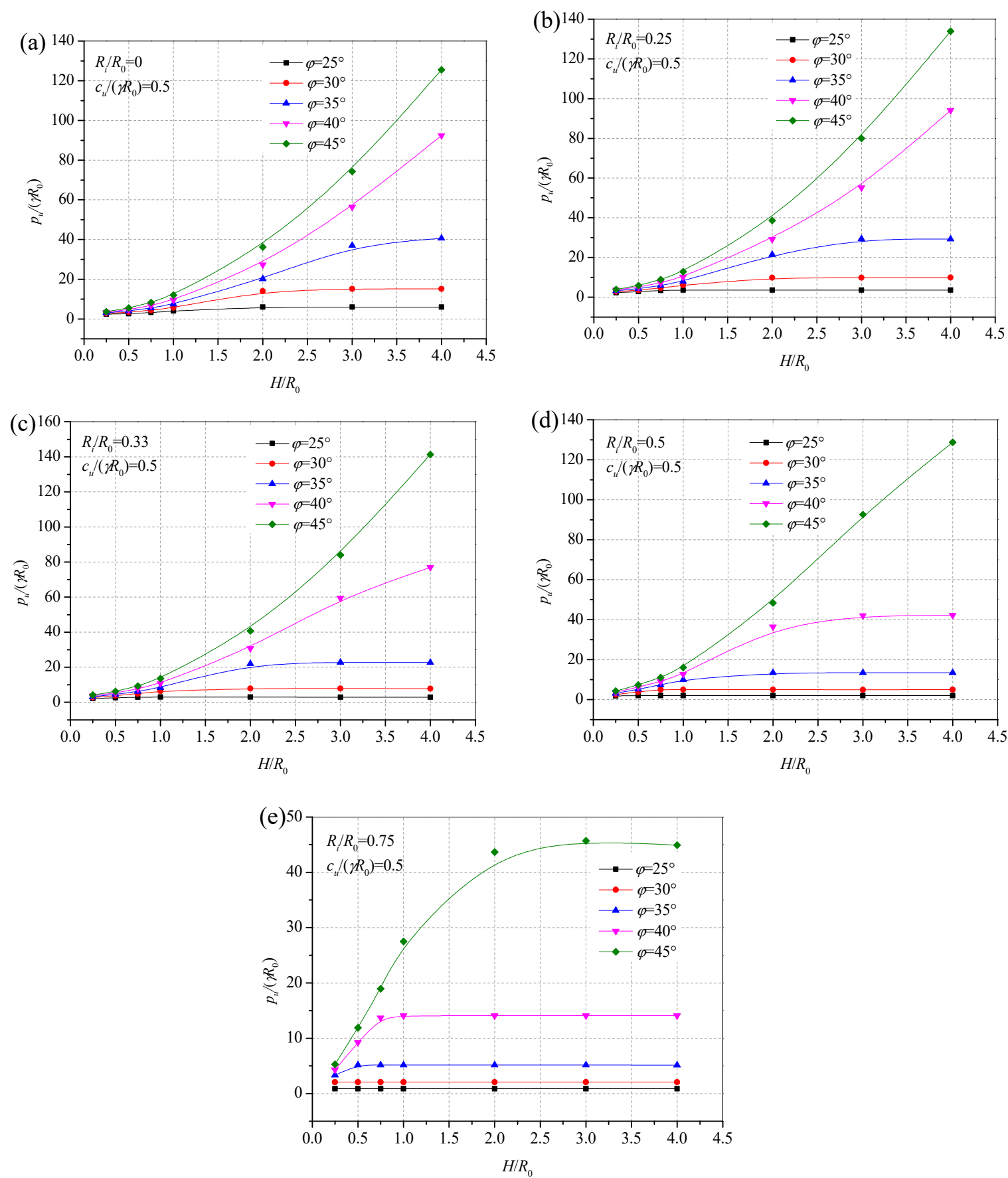

Figure 6. Variation in the normalized bearing capacity, $p /\left(\gamma R_{0}\right)$, with $H / R_{0}$ and $\varphi$ for $c_{u} /\left(\gamma R_{0}\right)=0.5$ with (a) $R_{i} / R_{0}=0$, (b) $R_{i} / R_{0}=0.25$, (c) $R_{i} / R_{0}=0.33$, (d) $R_{i} / R_{0}=0.5$, and (e) $R_{i} / R_{0}=0.75$.

\subsection{Effect of the Undrained Shear Strength of the Clay $\left(c_{u} / \gamma R_{0}\right)$}

The predictions of the normalized bearing capacity $p_{u} /\left(\gamma R_{0}\right)$ for different combinations of $c_{u} /\left(\gamma R_{0}\right)$ and $\varphi$ are plotted in Figure 3 for the cases of $H / R_{0}=1$ and $R_{i} / R_{0}$, ranging from 0 to 0.75 . These plots clearly reveal that the bearing capacity increases non-linearly with an increase in the value of $c_{u} /\left(\gamma R_{0}\right)$. In most of the cases, the increase in the bearing capacity of ring footings reaches constant values at certain values of $c_{u} /\left(\gamma R_{0}\right)$. For example, considering the case of $H / R_{0}=1, R_{i} / R_{0}=0.25$, and $\varphi=30^{\circ}$, $p_{u} /\left(\gamma R_{0}\right)$ reaches a constant value of 9.93 at $c_{u} /\left(\gamma R_{0}\right)=2$. It indicates that the clayey stratum does not affect the bearing capacity when $c_{u} /\left(\gamma R_{0}\right)$ exceeds a certain value. This can be confirmed by the failure mechanisms shown in Figure 8. From the collapse mechanisms for different values of $c_{u} /\left(\gamma R_{0}\right)$, 
it can be seen that the depth of the failure mechanisms decreases with increasing the value of $c_{u} /\left(\gamma R_{0}\right)$, and eventually does not exceed the sand layer. This finding is similar to the previous studies conducted by Shiau et al. [3] for strip footings and by Kumar and Chakraborty [30] for circular foundations.

However, for the cases of $\varphi=35^{\circ}$ with $R_{i} / R_{0} \leq 0.25$ and $\varphi=40^{\circ}$ to $45^{\circ}$ with $R_{i} / R_{0} \leq 0.5$, as the value of $c_{u} /\left(\gamma R_{0}\right)$ increases, the bearing capacity increases continuously, and the rate increase in bearing capacity decreases. It is implied that when the value of $\varphi$ increases, the bearing capacity reaching a constant value needs a larger magnitude for $c_{u} /\left(\gamma R_{0}\right)$. This observation can be explained by the failure patterns for different values of $\varphi$, as presented in Figure 9, indicating that the failure mechanisms extend from the sand layer to the underlying clay when the value of $\varphi$ increases. Thus, for the sand layer with larger values of $\varphi$, it requires a larger magnitude of $c_{u} /\left(\gamma R_{0}\right)$ to constrain the failure mechanisms within the sand layer, when the bearing capacity becomes independent of $c_{u} /\left(\gamma R_{0}\right)$. A similar tendency can also be observed in the work by Kumar and Chakraborty [30]. Interestingly, at a given value of $H / R_{0}=1$, the shear strength of the clay has a negligible influence on the bearing capacity for smaller magnitudes of $\varphi$ and larger values of $R_{i} / R_{0}$. This may be attributed to fact that the value of $R_{i} / R_{0}=1$ exceeds the critical depth (beyond which no further improvement occurs) of the sand layer, which is discussed later.

\subsection{Effect of the Ratio of the Internal Radius to the External Radius of the Footing $\left(R_{i} / R_{0}\right)$}

The variations of the normalized bearing capacity, $p /\left(\gamma R_{0}\right)$, for different combinations of $R_{i} / R_{0}$ and $\varphi$ are illustrated in Figure 4 for the cases of $c_{u} /\left(\gamma R_{0}\right)=0.5$ and $H / R_{0}=0.5$ to 4 and Figure 5 for the cases of $H / R_{0}=1$ and $c_{u} /\left(\gamma R_{0}\right)=0.25$ to 5 . These results may be classified into three types. (1) The bearing capacity increases continuously with increasing $R_{i} / R_{0}$ for the example of $H / R_{0}=1, c_{u} /\left(\gamma R_{0}\right)$ $=0.5$, and $\varphi=45^{\circ}$, and the rate of increase of $p /\left(\gamma R_{0}\right)$ increases. (2) As the value of $R_{i} / R_{0}$ increases, the bearing capacity first increases, and then decrease. Considering the case of $H / R_{0}=1, c_{u} /\left(\gamma R_{0}\right)=1$, and $\varphi=35^{\circ}$, for example, $p /\left(\gamma R_{0}\right)$ increases from 10.72 for $R_{i} / R_{0}=0$ to 13.66 for $R_{i} / R_{0}=0.5$, and then decreases to 5.16 for $R_{i} / R_{0}=0.75$. (3) The bearing capacity decreases continuously with an increase in the magnitude of $R_{i} / R_{0}$, for the example of $H / R_{0}=2, c_{u} /\left(\gamma R_{0}\right)=0.5$, and $\varphi=30^{\circ}$.

For the type (2) of the results, however, the magnitude of $R_{i} / R_{0}$ for the bearing capacity reaching the maximum value is affected by $H / R_{0}, c_{u} /\left(\gamma R_{0}\right)$ and $\varphi$, which should be discussed at length. In Figure 4 , for a given value of $\varphi=35^{\circ}, p /\left(\gamma R_{0}\right)$ reaches the maximum value approximately at $R_{i} / R_{0}=0.6$ for $H / R_{0}=0.5, R_{i} / R_{0}=0.5$ for $H / R_{0}=1, R_{i} / R_{0}=0.33$ for $H / R_{0}=2$, and $R_{i} / R_{0}=0$ for $H / R_{0}=4$, respectively. It may be concluded that the value of $R_{i} / R_{0}$ for the bearing capacity reaching the maximum value decreases with increasing $H / R_{0}$. Based on Figure 5, for a given value of $\varphi=35^{\circ}, p /\left(\gamma R_{0}\right)$ reaches the maximum value approximately at $R_{i} / R_{0}=0.55$ for $c_{u} /\left(\gamma R_{0}\right)=0.25, R_{i} / R_{0}=0.5$ for $c_{u} /\left(\gamma R_{0}\right)=1$, $R_{i} / R_{0}=0.33$ for $c_{u} /\left(\gamma R_{0}\right)=2$ and $R_{i} / R_{0}=0.2$ for $c_{u} /\left(\gamma R_{0}\right)=5$, respectively. Therefore, it also can be found that the value of $R_{i} / R_{0}$ for the bearing capacity reaching the maximum value decreases with increasing $c_{u} /\left(\gamma R_{0}\right)$. Considering the case of $H / R_{0}=2$ and $c_{u} /\left(\gamma R_{0}\right)=0.5, p /\left(\gamma R_{0}\right)$ reaches the maximum value approximately at $R_{i} / R_{0}=0.55$ for $\varphi=45^{\circ}, R_{i} / R_{0}=0.5$ for $\varphi=40^{\circ}, R_{i} / R_{0}=0.33$ for $\varphi=35^{\circ}$, and $R_{i} / R_{0}=0$ for $\varphi=30^{\circ}$, respectively. It can therefore be concluded that the value of $R_{i} / R_{0}$ for the bearing capacity reaching the maximum value decreases with an increase in the magnitude of $\varphi$. It needs to be mentioned that the similar trends can be observed in the work by Kumar and Chakraborty [30] for bearing capacity factors of ring footings.

\subsection{Effect of the Thickness of the Sand Layer $\left(H / R_{0}\right)$}

The variations of the normalized bearing capacity $p /\left(\gamma R_{0}\right)$ with different magnitudes of $H / R_{0}$ and $\varphi$ are shown in Figure 6 for the cases of $c_{u} /\left(\gamma R_{0}\right)=0.5$ and $R_{i} / R_{0}=0$ to 0.75 . These figures clearly indicate the existence of the critical thickness, $H_{c}$, of the sand layer beyond which $p /(\gamma B)$ reaches a constant value. For the example of $R_{i} / R_{0}=0.5, c_{u} /\left(\gamma R_{0}\right)=0.5$, and $\varphi=40^{\circ}$, it can be seen that $p /(\gamma B)$ reaches a constant value of 42.07 approximately at $H / R_{0}=3$. That is, when the depth of the sand layer exceeds $H_{c}$, the collapse mechanism develops within the sand layer. The failure mechanisms for 
different $H / R_{0}$ illustrated in Figure 11 can be used to confirm this finding. However, considering the case of $R_{i} / R_{0}=0.25, c_{u} /\left(\gamma R_{0}\right)=0.5$, and $\varphi=45^{\circ}$, for example, it seems that a critical thickness does not exist. In fact, for larger values of $\varphi$ and smaller magnitudes of $R_{i} / R_{0}$, the value of critical depth will become larger. This can be supported by Figure 7 for the variation of $H_{c} / R_{0}$. It is noteworthy that a similar tendency can be observed from a previous study reported by Kumar and Chakraborty [30]. As expected, the critical thickness ratio, $H_{c} / R_{0}$, depends on $R_{i} / R_{0}, c_{u} /\left(\gamma R_{0}\right)$, and $\varphi$. Figure 7 shows the variations of $H_{c} / R_{0}$ for different combinations of $R_{i} / R_{0}, c_{u} /\left(\gamma R_{0}\right)$, and $\varphi$. In general, the value of $H_{c} / R_{0}$ decreases with decreases in $\varphi$ and increases in $R_{i} / R_{0}$ and $c_{u} /\left(\gamma R_{0}\right)$.
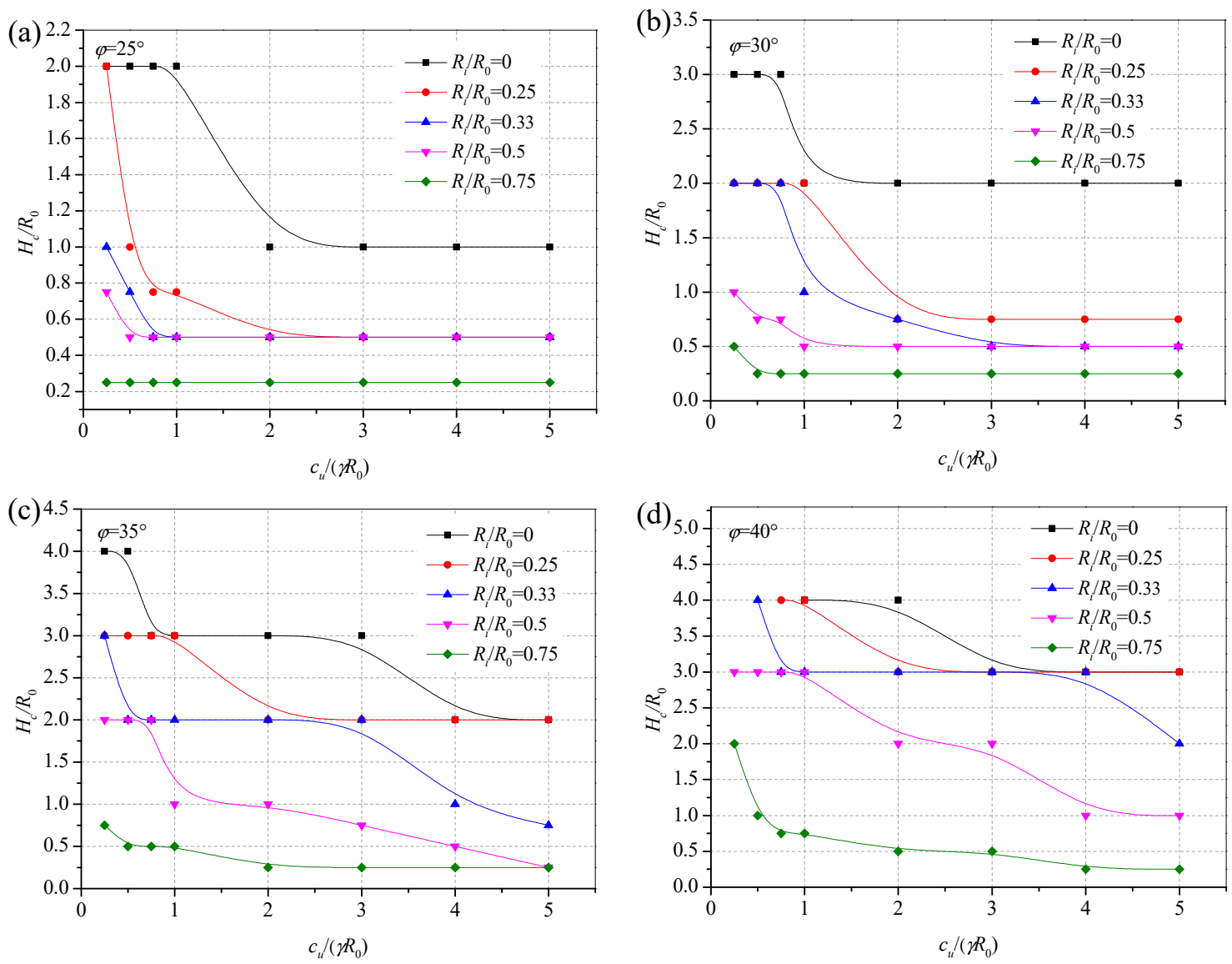

Figure 7. Variation in the critical thickness, $H / R_{0}$, with $c_{u} /\left(\gamma R_{0}\right)$ and $R_{i} / R_{0}$ for (a) $\varphi=25^{\circ}$, (b) $\varphi=30^{\circ}$, (c) $\varphi=35^{\circ}$, and (d) $\varphi=40^{\circ}$.

\subsection{Failure Mechanisms}

With $R_{i} / R_{0}=0.5, \varphi=35^{\circ}$, and $H / R_{0}=0.5$, Figure 8 illustrates the failure mechanisms for four different magnitudes of $c_{u} /\left(\gamma R_{0}\right)$, namely $0.5,1,3$, and 5. For $c_{u} /\left(\gamma R_{0}\right)=0.5$ and 1 , two rupture lines develop from both external and internal edges of the ring footing to the bottom of the sand layer, and the log-spiral lines extend from the underlying clay to the upper sand layer. On the other hand, for $c_{u} /\left(\gamma R_{0}\right)=3$ and 5 , the failure patterns are confined only within the sand layer, with a non-plastic triangular wedge below the ring footing base, and the slip lines extend to the free surface. This is similar to the classical shallow footing mechanism. 

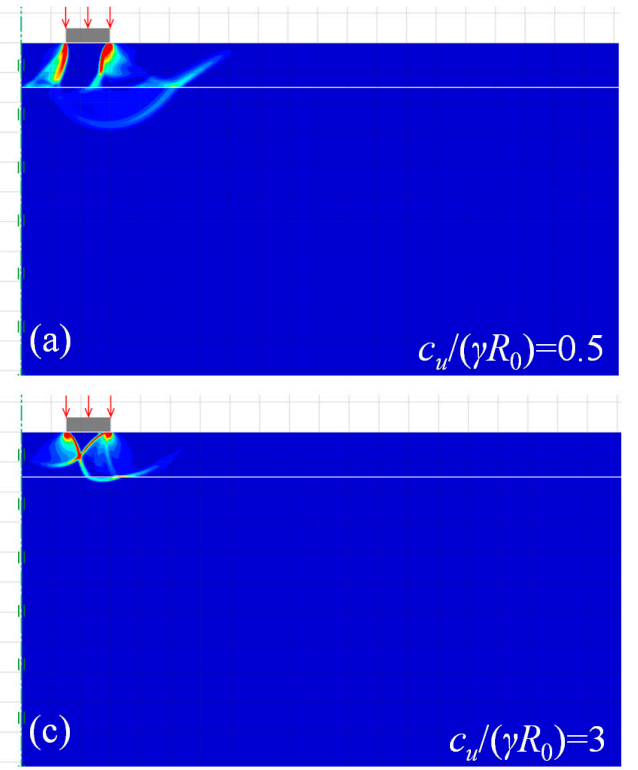
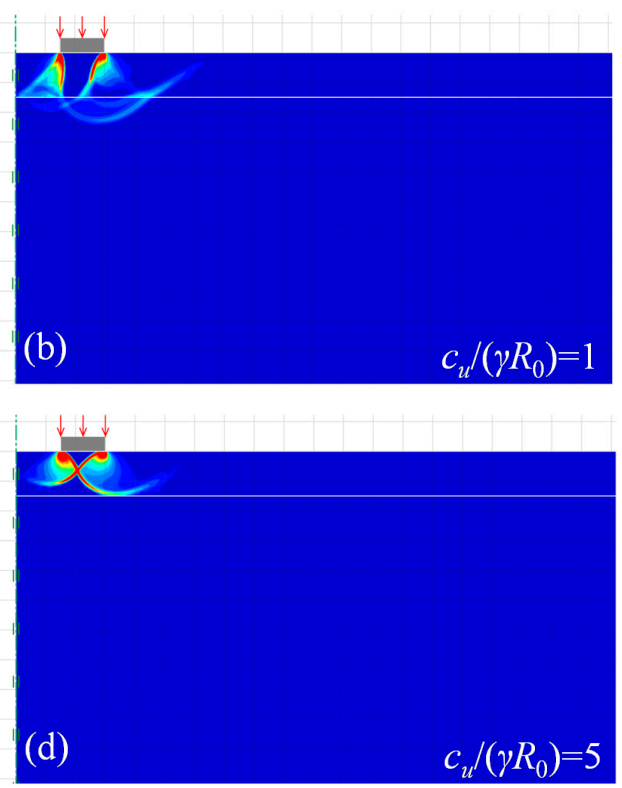

Figure 8. Upper bound collapse mechanisms for $R_{i} / R_{0}=0.5, \varphi=35^{\circ}$, and $H / R_{0}=0.5$ with (a) $c_{u} /\left(\gamma R_{0}\right)=0.5,(\mathbf{b}) c_{u} /\left(\gamma R_{0}\right)=1$, (c) $c_{u} /\left(\gamma R_{0}\right)=3$, and (d) $c_{u} /\left(\gamma R_{0}\right)=5$.

Figure 9 presents the variation in failure mechanisms with the variations in magnitudes for $\varphi$ from $25^{\circ}$ to $45^{\circ}$, with $R_{i} / R_{0}=0.5, c_{u} /\left(\gamma R_{0}\right)=1$, and $H / R_{0}=0.75$. For $\varphi=25^{\circ}$ and $30^{\circ}$, the failure modes are developed only within the sand layer. On the other hand, for $\varphi=35^{\circ}, 40^{\circ}$, and $45^{\circ}$, the slip lines of the sand block extend from the external edge of the ring footing to the upper surface of the clay layer, and the rupture lines develop from the clayey strata to the upper sand layer. It should be noted that the size of the plastic zone decreases as the value of $\varphi$ decreases. Therefore, as the value of $\varphi$ increases, the proportion of the collapse mechanism in the clay layer increases, giving rise to the possibility of punching shear failure [3,7].
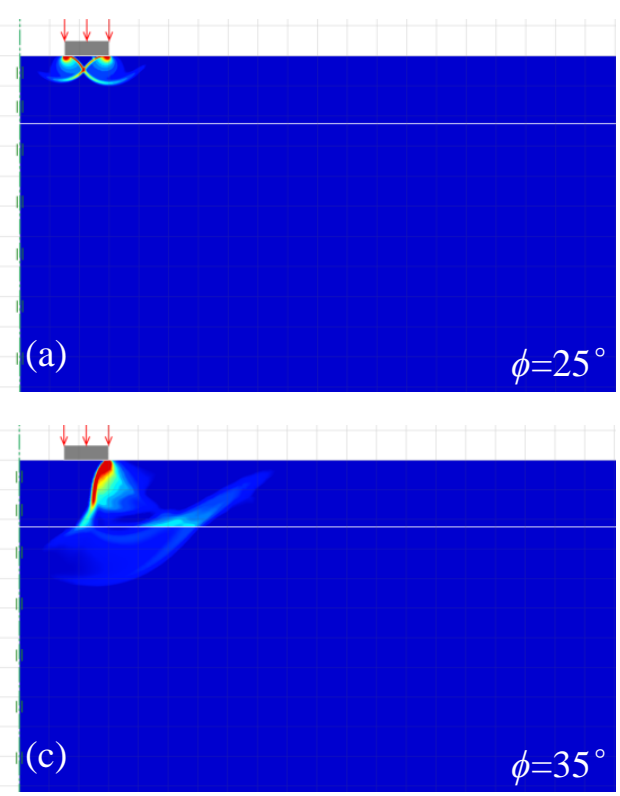
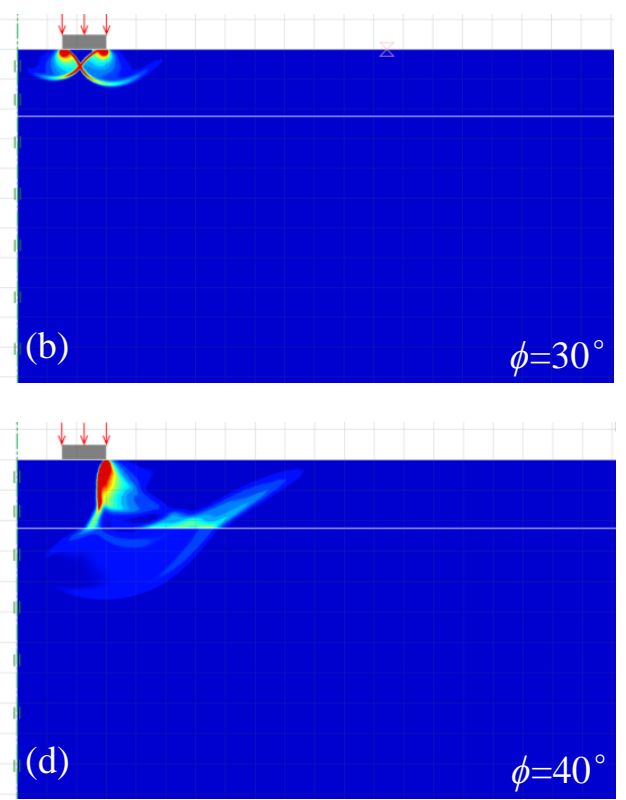

Figure 9. Cont. 


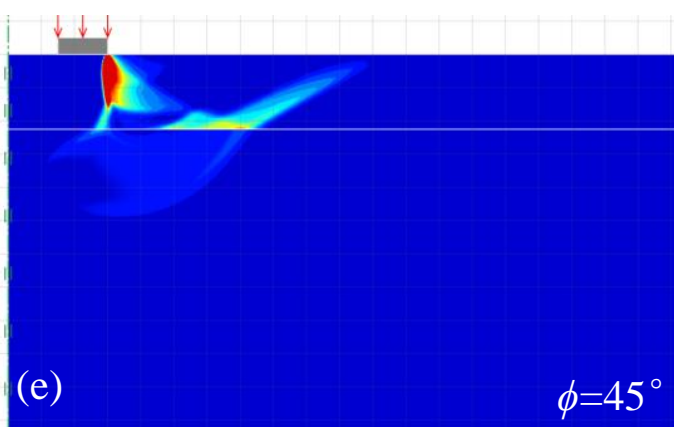

(e)

Figure 9. Upper bound collapse mechanisms for $R_{i} / R_{0}=0.5, c_{u} /\left(\gamma R_{0}\right)=1, H / R_{0}=0.75$ with (a) $\varphi=25^{\circ}$, (b) $\varphi=30^{\circ}$, (c) $\varphi=35^{\circ}$, (d) $\varphi=40^{\circ}$, and (e) $\varphi=45^{\circ}$.

Figure 10 shows the failure mechanisms for different $R_{i} / R_{0}$ with $\varphi=35^{\circ}, c_{u} /\left(\gamma R_{0}\right)=2$, and $H / R_{0}=0.75$. For the cases of $R_{i} / R_{0}=0,0.25$, and 0.33 , the failure modes are similar to Figure 9c-e. It needs to be mentioned that the failure surface in the sand layer inclines to the center line of the footing. From Figure $10 \mathrm{~d}$ for $R_{i} / R_{0}=0.5$ and Figure $10 \mathrm{e}$ for $R_{i} / R_{0}=0.75$, it can be seen that the clayey stratum does not affect the collapse mechanisms. In addition, the size of the failure zone decreases with an increase in the value of $R_{i} / R_{0}$, which also can be observed in Figure 10. Several failure modes for different $H / R_{0}$ with $\varphi=35^{\circ}, c_{u} /\left(\gamma R_{0}\right)=2$, and $R_{i} / R_{0}=0.5$ are illustrated in Figure 11 . A critical thickness can be clearly seen. Interestingly, the failure mechanics for $H / R_{0}=1$ and 3 are exactly the same. Therefore, it can be concluded that the collapse mechanics do not change when the thickness of the sand layer exceeds the critical depth.
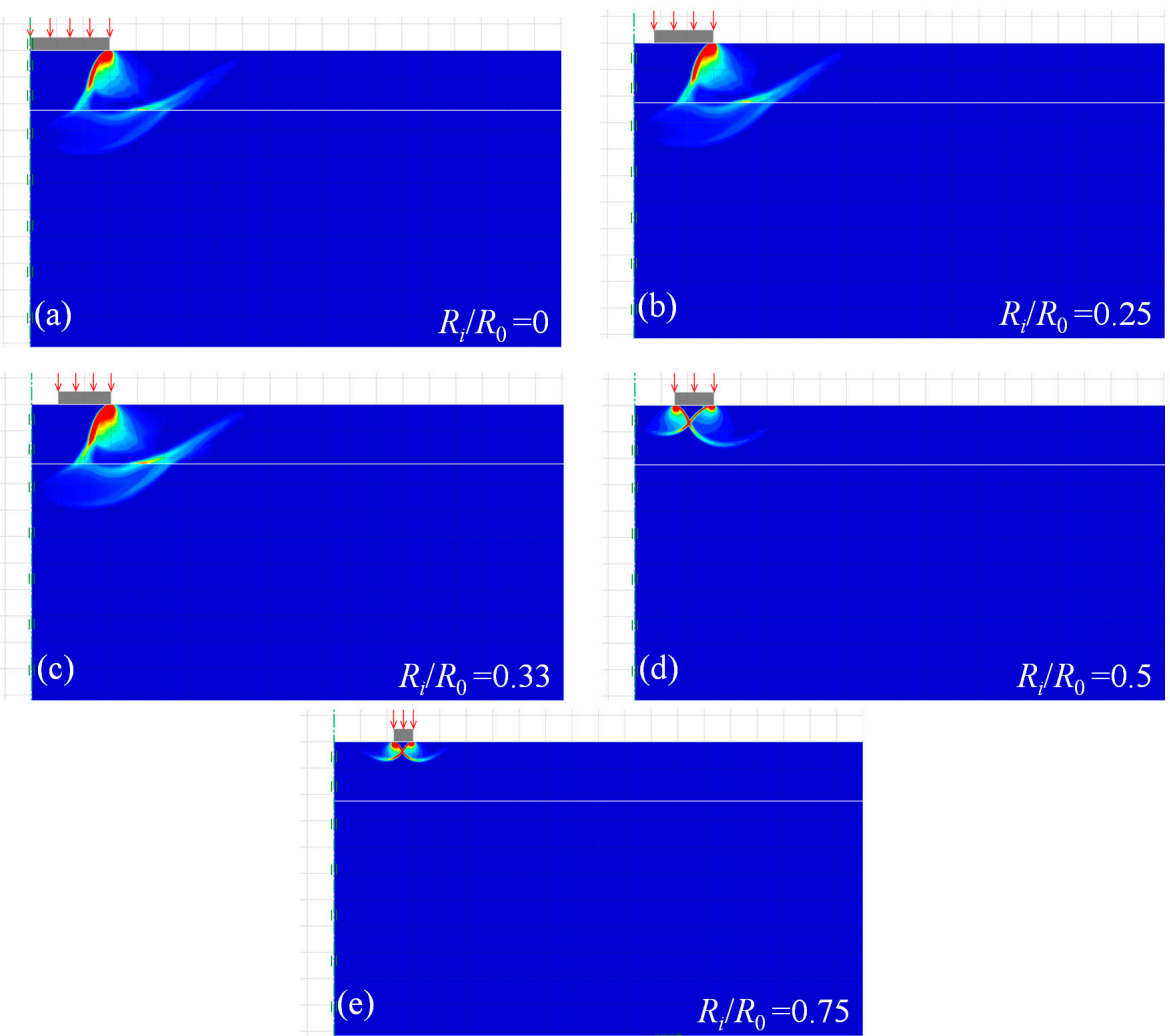

Figure 10. Upper bound collapse mechanisms for $\varphi=35^{\circ}, c_{u} /\left(\gamma R_{0}\right)=2, H / R_{0}=0.75$ with $(\mathbf{a}) R_{i} / R_{0}=0$, (b) $R_{i} / R_{0}=0.25$, (c) $R_{i} / R_{0}=0.33$, (d) $R_{i} / R_{0}=0.5$, and (e) $R_{i} / R_{0}=0.75$. 

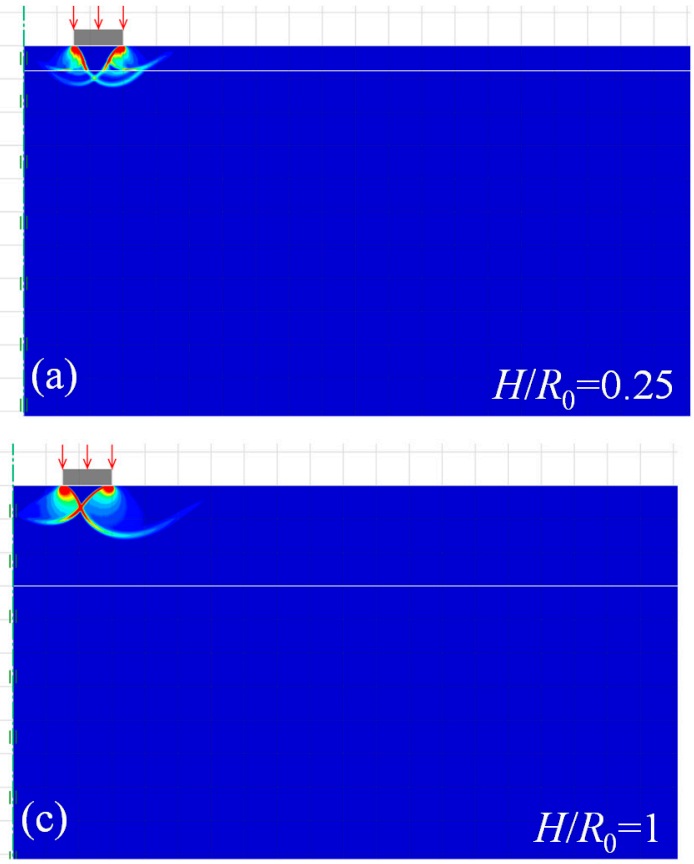
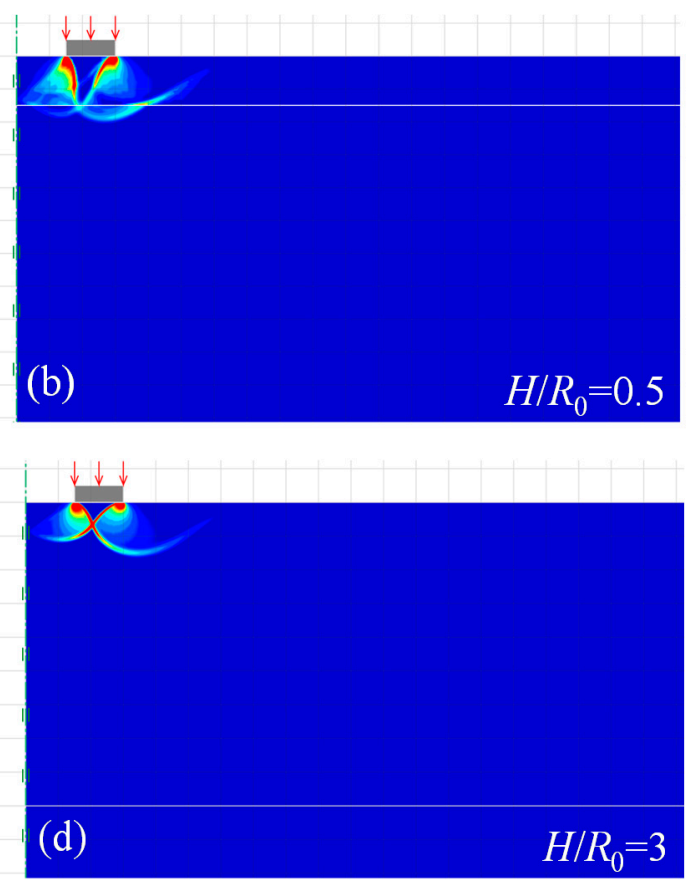

Figure 11. Upper bound collapse mechanisms for $R_{i} / R_{0}=0.5, \varphi=35^{\circ}, c_{u} /\left(\gamma R_{0}\right)=2$ with $(\mathbf{a}) H / R_{0}=0.25$, (b) $H / R_{0}=0.5$, (c) $H / R_{0}=1$, and (d) $H / R_{0}=3$.

\section{Conclusions}

The ultimate bearing capacity of rough ring footings on sand overlying clay was evaluated. Using FELA, the normalized bearing capacity, $p /\left(\gamma R_{0}\right)$, was calculated for a wide range of parameters. The effect of the undrained shear strength, $c_{u} /\left(\gamma R_{0}\right)$, of the clay, the thickness $H / R_{0}$, the friction angle, $\varphi$, of the sand layer, and the ratio of the inner to the outer radii, $R_{i} / R_{0}$, of the foundation on $p /\left(\gamma R_{0}\right)$ was also investigated. The results obtained from the present study are found to match reasonably well with existing solutions. To facilitate use among engineers, design charts are provided. Based on the limit analysis results, the following conclusions can be made.

(1) The bearing capacity reaches a constant value when $H / R_{0}$ exceeds the critical thickness $H_{c} / R_{0}$, which depends on the magnitudes of $\varphi, R_{i} / R_{0}$, and $c_{u} /\left(\gamma R_{0}\right)$. In general, the value of $H_{c} / R_{0}$ decreases with decreases in $\varphi$ and increases in $R_{i} / R_{0}$ and $c_{u} /\left(\gamma R_{0}\right)$. For $H / R_{0}<H_{c} / R_{0}$, the bearing capacity increases continuously with an increase in the value of $c_{u} /\left(\gamma R_{0}\right), H / R_{0}$, and $\varphi$.

(2) For $H / R_{0}<H_{c} / R_{0}$, the values of $p /\left(\gamma R_{0}\right)$ tend to become maximum corresponding to a certain value of $R_{i} / R_{0}$. The magnitude of $R_{i} / R_{0}$ for the bearing capacity reaching the maximum value decreases with increasing $c_{u} /\left(\gamma R_{0}\right), H / R_{0}$, and $\varphi$. On the other hand, with smaller values of $c_{u} /\left(\gamma R_{0}\right), H / R_{0}$, and $\varphi$, the value of $p /\left(\gamma R_{0}\right)$ increases continuously with increasing $R_{i} / R_{0}$ and decreases continuously with increasing $R_{i} / R_{0}$ for larger values of $c_{u} /\left(\gamma R_{0}\right), H / R_{0}$, and $\varphi$.

(3) For $H / R_{0} \geq H_{c} / R_{0}$, the collapse mechanism is confined only within the sand layer, which is similar to the classical shallow footing mechanism. For $H / R_{0}<H_{\mathcal{C}} / R_{0}$, the punching shear failure occurs in the sand layer, and the log-spiral rupture lines develop from the clayey strata to the upper sand layer.

Author Contributions: Writing—original draft, C.Y.; software, Z.Z.; validation, Z.Z.; writing—review and editing, Y.X. All authors have read and agreed to the published version of the manuscript.

Funding: This research was funded by National Natural Science Foundation of China, grant number 51908208.

Acknowledgments: The authors would like to acknowledge the financial support of the National Natural Science Foundation of China ((No. 51908208), which made the work presented in this paper possible.

Conflicts of Interest: The authors declare that there is no conflict of interest. 


\section{References}

1. Terzaghi, K. Theoretical Soil Mechanics; Wiley: New York, NY, USA, 1943.

2. Meyerhof, G.G. Some recent research on the bearing capacity of foundations. Can. Geotech. J. 1963, 1, 16-26. [CrossRef]

3. Hansen, J.B. A Revised and Extended Formula for Bearing Capacity; Bulletin No. 28; Danish Geotechnical Institute: Copenhagen, Denmark, 1970; p. 21.

4. Vesic, A.S. Analysis of ultimate loads of shallow foundations. J. Soil Mech. Found. Div. 1973, 99, 45-73. [CrossRef]

5. Shiau, J.S.; Lyamin, A.V.; Sloan, S.W. Bearing capacity of a sand layer on clay by finite element limit analysis. Can. Geotech. 2003, 40, 900-915. [CrossRef]

6. Terzaghi, K.; Peck, R.B. Soil Mechanics in Engineering Practice, 1st ed.; John Wiley and Sons: New York, NY, USA, 1948.

7. Meyerhof, G.G. Ultimate bearing capacity of footings on sand layer overlying clay. Can. Geotech. J. 1974, 11, 223-229. [CrossRef]

8. Hanna, A.M.; Meyerhof, G.G. Design charts for ultimate bearing capacity of foundations on sand overlying soft clay. Can. Geotech. J. 1980, 17, 300-303. [CrossRef]

9. Okamura, M.; Takemura, J.; Kimura, T. Bearing capacity predictions of sand overlying clay based on limit equilibrium methods. Soil Found. 1998, 38, 181-194. [CrossRef]

10. Lee, K.K.; Cassidy, M.J.; Randolph, M.F. Bearing capacity on sand overlying clay soils: Experimental and finite-element investigation of potential punch-through failure. Geotechnique 2013, 63, 1271-1284. [CrossRef]

11. Florkiewicz, A. Upper bound to bearing capacity of layered soils. Can. Geotech. J. 1989, 26, 730-736. [CrossRef]

12. Michalowski, R.L.; Shi, L. Bearing capacity of footings over two-layer foundation soils. J. Geotech. Eng. 1995, 121, 421-428. [CrossRef]

13. Huang, M.; Qin, H.L. Upper-bound multi-rigid-block solutions for bearing capacity of two-layered soils. Comput. Geotech. 2009, 36, 525-529. [CrossRef]

14. Burd, H.J.; Frydman, S. Bearing capacity of plane-strain footings on layered soils. Can. Geotech. J. 1997, 34, 241-253. [CrossRef]

15. Ornek, M.; Demir, A.; Laman, M.; Yildiz, A. Numerical analysis of circular footings on natural clay stabilized with a granular fill. Acta Geotech. Slov. 2012, 1, 61-75.

16. Park, J.S.; Park, D. Vertical bearing capacity of bucket foundation in sand overlying clay. Ocean Eng. 2017, 134, 62-76. [CrossRef]

17. Kumar, J.; Chakraborty, M. Bearing capacity of a circular foundation on layered sand-clay media. Soils Found. 2015, 55, 1058-1068. [CrossRef]

18. Craig, W.H.; Chua, K. Deep penetration of spud-can foundations on sand and clay. Geotechnique 1990, 40, 541-556. [CrossRef]

19. Okamura, M.; Takemura, J.; Kimura, T. Centrifuge model tests on bearing capacity and deformation of sand layer overlying clay. Soils Found. 1997, 37, 73-88. [CrossRef]

20. Lee, K.K.; Randolph, M.F.; Cassidy, M.J. Bearing capacity on sand overlying clay soils: A simplified conceptual model. Geotechnique 2013, 63, 1285-1297. [CrossRef]

21. Ohri, M.; Purhit, D.; Dubey, M. Behavior of ring footing on dune sand overlying dense sand. In Proceedings of the International Conference on Civil Engineering, Tehran, Iran, 12 August 1997; pp. 22-24.

22. Hataf, N.; Razav, I.M. Behavior of ring footings on sand. Iran. J. Sci. Technol. Trans. B 2003, 27, 47-56.

23. Kumar, J.; Ghosh, P. Bearing capacity factor $N_{\gamma}$ for ring footings using the method of characteristics. Can. Geotech. J. 2005, 42, 1474-1484. [CrossRef]

24. Keshavarz, A.; Kumar, J. Bearing capacity computation for a ring foundation using the stress characteristics method. Comput. Geotech. 2017, 89, 33-42. [CrossRef]

25. Zhao, L.; Wang, J.H. Vertical bearing capacity for ring footings. Comput. Geotech. 2008, 35, 292-304. [CrossRef]

26. Benmebarek, S.; Remadna, M.S.; Benmebarek, N.; Belounar, L. Numerical evaluation of the bearing capacity factor of ring footings. Comput. Geotech. 2012, 44, 132-138. [CrossRef] 
27. Choobbasti, A.J.; Hesami, S.; Najafi, A.; Pirzadeh, S.; Farrokhzad, F.; Zahmatkesh, A. Numerical evaluation of bearing capacity and settlement of ring footing; case study of Kazeroon cooling towers. Int. J. Res. Rev. Appl. Sci. 2010, 4, 263-271.

28. Boushehrian, J.H.; Hataf, N. Experimental and numerical investigation of the bearing capacity of model circular and ring footings on reinforced sand. Geotext. Geomembr. 2003, 21, 241-256. [CrossRef]

29. Naderi, E.; Hataf, N. Model testing and numerical investigation of interference effect of closely spaced ring and circular footings on reinforced sand. Geotext. Geomembr. 2014, 42, 191-200. [CrossRef]

30. Kumar, J.; Chakraborty, M. Bearing capacity factors for ring foundations. J. Geotech. Geoenviron. Eng. 2015, 141, 06015007. [CrossRef]

31. Benmebarek, S.; Saifi, I.; Benmebarek, N. Undrained vertical bearing capacity factors for ring shallow footings. Geotech. Geol. Eng. 2017, 35, 1-10. [CrossRef]

32. Lee, J.K.; Jeong, S.; Lee, S. Undrained bearing capacity factors for ring footings in heterogeneous soil. Comput. Geotech. 2016, 75, 103-111. [CrossRef]

33. Lee, J.K.; Jeong, S.; Shang, J.Q. Undrained bearing capacity of ring foundations on two-layered clays. Ocean Eng. 2016, 119, 47-57. [CrossRef]

34. Lee, J.K.; Jeong, S. Immediate settlement of ring footing resting on inhomogeneous finite stratum. Appl. Sci. 2018, 8, 225. [CrossRef]

35. Sargazi, O.; Hosseininia, E.S. Bearing capacity of ring footings on cohesionless soil under eccentric load. Comput. Geotech. 2017, 92, 169-178. [CrossRef]

36. Krabbenhoft, K.; Lyamin, A.; Krabbenhoft, J. Optum Computational Engineering (OptumG2). 2020. Available online: www.optumce.com (accessed on 19 March 2020).

37. Lyamin, A.V.; Sloan, S.W. Lower bound limit analysis using non-linear programming. Int. J. Numer. Anal. Methods Eng. 2002, 55, 573-611. [CrossRef]

38. Lyamin, A.V.; Sloan, S.W. Upper bound limit analysis using linear finite elements and non-linear programming. Int. J. Numer. Anal. Methods Geomech. 2002, 26, 181-216. [CrossRef]

39. Krabbenhoft, K.; Lyamin, A.V.; Hjiaj, M.; Sloan, S.W. A new discontinuous upper bound limit analysis formulation. Int. J. Numer. Anal. Methods Eng. 2005, 63, 1069-1088. [CrossRef]

40. Krabbenhøft, K.; Lyamin, A.V.; Sloan, S.W. Formulation and solution of some plasticity problems as conic programs. Int. J. Solids Struct. 2007, 44, 1533-1549. [CrossRef]

41. Sloan, S.W. Geotechnical stability analysis. Geotechnique 2013, 63, 531-571. [CrossRef]

42. Potts, D.M.; Zdravkovic, L.; Zdravković, L. Finite Element Analysis in Geotechnical Engineering: Application; Thomas Telford: London, UK, 2001.

43. Salgado, R.; Lyamin, A.V.; Sloan, S.W.; Yu, H.S. Two-and three-dimensional bearing capacity of foundations in clay. Geotechnique 2004, 54, 297-306. [CrossRef]

44. Meyerhof, G.G. The ultimate bearing capacity of foudations. Geotechnique 1951, 2, 301-332. [CrossRef]

45. Tani, K.; Craig, W. Bearing capacity of circular foundations on soft clay of strength increasing with depth. Soils Found. 1995, 35, 21-35.

46. Houlsby, G.T.; Martin, C.M. Undrained bearing capacity factors for conical footings on clay. Geotechnique 2003, 53, 513-520. [CrossRef]

47. Martin, C.M. ABC-Analysis of Bearing Capacity. 2004. Available online: www-civil.eng.ox.ac.uk/people/ $\mathrm{cmm} / \mathrm{software} / \mathrm{abc}$ (accessed on 26 March 2020).

48. Skempton, A.W. The bearing capacity of clays. In Proceedings of the Building Research Congress, London, UK, 9 September 1951; Part 1, pp. 180-189.

49. Edwards, D.H.; Zdravkovic, L.; Potts, D.M. Depth factors for undrained bearing capacity. Geotechnique 2005, 55, 755-758. [CrossRef]

50. Gourvenec, S.; Randolph, M.; Kingsnorth, O. Undrained bearing capacity of square and rectangular footings. J. Geomech. 2006, 6, 147-157. [CrossRef]

51. Taiebat, H.A.; Carter, J.P. A failure surface for circular footings on cohesive soils. Geotechnique 2010, 60, 265-273. [CrossRef]

52. Kusakabe, O.; Suzuki, H.; Nakase, A. An upper bound calculation on bearing capacity of a circular footing on a non-homogeneous clay. Soils Found. 1986, 26, 143-148. [CrossRef]

53. Khatri, V.N.; Kumar, J. Bearing capacity factor $N_{\gamma}$ for a rough conical footing. Geomech. Eng. 2009, 1, $205-218$. [CrossRef] 
54. De Simone, P. Bearing capacity of a circular footing on a Coulomb medium. In Proceedings of the 5 th International Conference Numerical Methods Geomechanics, Nayoya, Japan, 1-5 April 1985; Volume 2, pp. 829-836.

55. Erickson, H.L.; Drescher, A. Bearing capacity of circular footings. J. Geotech. Geoenviron. Eng. 2002, 128, 38-43. [CrossRef]

56. Lyamin, A.V.; Salgado, R.; Sloan, S.W.; Prezzi, M. Two-and three-dimensional bearing capacity of footings in sand. Geotechnique 2007, 57, 647-662. [CrossRef]

57. Kumar, J.; Khatri, V.N. Bearing capacity factors of circular foundations for a general $c-\varphi$ soil using lower bound finite elements limit analysis. Int. J. Numer. Anal. Methods Geomech. 2011, 35, 393-405. [CrossRef]

58. Loukidis, D.; Salgado, R. Bearing capacity of strip and circular footings in sand using finite elements. Comput. Geotech. 2009, 36, 871-879. [CrossRef]

(C) 2020 by the authors. Licensee MDPI, Basel, Switzerland. This article is an open access article distributed under the terms and conditions of the Creative Commons Attribution (CC BY) license (http://creativecommons.org/licenses/by/4.0/). 